\title{
DESIGNING ORPHANAGE WITH THE APPROACH OF CREATING SENSE OF BELONGING TO THE ENVIRONMENT
}

\author{
Anahita Khanbabaei \\ Department of Architecture,Damghan Branch,Islamic Azad University,Damghan,Iran
}

\begin{abstract}
Children how grow up in a family environment with no love and attachment in an unsafe environment would be under emotional, ethical, social and metal crises. Although the crises make same children involved apparently; in deeper concept and in nature, they make whole society involved in it. One of the difficulties of the society is the issue of orphans. These are innocent children who have lost their family under specific conditions and have become orphan forcibly. In fact, orphan children are victims of the society, a society that has not only deprived them from having warm family that is their natural right, but also can't accept them and looks them as scoria. Problems of these children is lack of sense of security and meeting their needs, lack of self-confidence and lack of expressing problems with right person and lack of being loved by others are other shortcomings and mental and behavioral problems of these children. Deprivation of orphans from presence of parents as basic foundations of family system makes challenge for growth of their positive self-concept more than before. Deprivation of natural function of family can affect not only self-concept of orphans, but also it can affect their perception of future. Disappointed child is a child with negative attitude to him/herself and to future and compared to other children, the children experience less safe attachment in relation with a caretaker. However, need to belonging is a comprehensive need. Belonging means that desire to creating a sustainable social relationship and threatening this need in any manner can cause sense of loneliness. In fact, loneliness is a cognitive and emotional reaction to this threat and demonstrates that there is a gap between actual social relationship of person and desired social relationship. In this study, it has been tried to consider important factors to create sense of belonging to the environment in children to design a space for them, so that they can feel to be a member of society and feel less unsafe and alienation with the environment.
\end{abstract}

Keywords: Sense of belonging to environment, children, orphan, family

\section{INTRODUCTION}

Presence of orphans at the societies has made the societies doesn't consider them as society members and separate them from other people. Through designing the centers, it has been tried to create sense of belonging to the environment in these individuals, so that they can consider themselves as society members and the probable crime at the society can be declined.

\section{GOALS OF THE PROJECT}

The project follows two main goals as follows:

1- $\quad$ Considering needs of children to achieve a desirable and optimized system to decline results of orphanage.

2- $\quad$ Achieving to a standard pattern to design the centers considering climatic and native issues.

\section{HYPOTHESES}

Achieving to proper idea and design to:

1- Consider needs of children to achieve a desirable and optimal system to decline results of orphanage.

2- $\quad$ Achieving to a standard design pattern of these centers considering climatic and native issues.

\section{RESEARCH OBJECTIVES}

The project follows 2 main objectives as follows: 
Considering needs of children to achieve a desirable and optimized system to decline results of orphanage

Achieving to a standard pattern to design the centers considering climatic and native issues

Recognition of children is a combination of physical and social factors. Behavior and experiences of a child are highly depended on biologic, environmental and social factors. Lack of paying attention to each mentioned factor can affect change in physical factors and mental factors of child and can lead to irreparable damages.

One of the most important issues to meet these needs is a space, at which child grows up. Space and environment can affect physical and mental growth of children. Estimation of each effective need in growth of child needs a space to encompass all factors and instruments to meet needs and provide required conditions.

Architecture as a field that defines spatial and environmental quality for people is able to have proper behavior against this issue and can achieve a proper idea and implement it in suitable designing form through considering conditions of users. Hence, this study is focused on these centers and required space in regard with this goal and their architecture.

\section{REASONS AND IMPORTANCE OF CHOOSING THE SUBJECT}

Recognition of children is a combination of physical and social factors. Behavior and experiences of a child are highly depended on biologic, environmental and social factors. Lack of paying attention to each mentioned factor can affect change in physical factors and mental factors of child and can lead to irreparable damages.

One of the most important issues to meet these needs is a space, at which child grows up. Space and environment can affect physical and mental growth of children. Estimation of each effective need in growth of child needs a space to encompass all factors and instruments to meet needs and provide required conditions.

Architecture as a field that defines spatial and environmental quality for people is able to have proper behavior against this issue and can achieve a proper idea and implement it in suitable designing form through considering conditions of users. Hence, this study is focused on these centers and required spaces in regard with this goal and their architecture.

These centers are divided to two groups:

- $\quad$ Centers for supplying services to ordinary children (Children 'hospital, Kindergarten, Center for Intellectual Development, house of culture for children, primary school)

- Centers for supplying service to children with special conditions (Correction and Rehabilitation Center for children, unaccompanied child care centers, nursery, care centers for child with physical and motor disabilities, schools for exceptional children)

The centers are complexes that should be created because of inattention to primary needs of children. The centers and spaces are not only responsible for meeting primary needs of children, but also they are responsible for educating, rehabilitation and maintaining them that are responsibilities of families. Hence, the centers have special features that need specific consideration and designers of these spaces should consider them.

Children in these centers are left and orphan children that there are also some children among them that suffer from physical and mental disabilities. These children are deprived not only from support of their families, but also they are deprived from supports of the society. In some cases that society supports them, it has not been able to meet even a part of their needs. 
Visiting care centers for these children also demonstrates this issue. Majority of the centers have not required facilities. In cases that they are acceptable in terms of physical facilities, dominant emotional and mental space on them has been questionable.

Finally, due to the mentioned, designing a residential-care center with required facilities and equipment for orphans is considered. However, the centers should be able to supply service to ordinary children to make relationship of the centers with the society.

\section{METHODOLOGY}

In order to achieve to criteria and basis of the project to create a suitable environment for orphans and be responsible for some needs and be a center to meet their rights, it is necessary to have firstly enough and required recognition of the children and existential reason and increase in their number and also their mental and behavioral characteristics.

The mentioned issues have been formed based on following classification:

- Library studies: in order to use global experiences and existing problems in Iran and recognition of mental, spiritual and physical traits of different growth ages of children, relevant regulations and issues about orphanage, books, magazines and MA theses have been applied.

- $\quad$ Statistical studies: statistics of orphans or unsupervised children, determining population of the project and other issues based on available statistics of Welfare Administration or other relevant authorities

- Interview with authorities and experts of care affairs of orphans and using their opinions has been effective in detecting spirits and personalities of the children

It should be mentioned that among all data collection sources, field studies, questionnaire and in person visits have played the key role in providing and codifying the project.

\section{ENSE OF BELONGING TO THE ENVIRONMENT}

General sense to the environment after perception and judgment on the environment is the sense of place and environment that is important factor to match person and environment. it can cause better utilization of the environment and satisfaction of users and final, their sense of belonging to the environment and continuity of their presence in the environment.

This kind of belonging is derived from physical elements and components of the environment as a part of recognition process and human identity. Rijeroes lav Arcas has referred in his studies to important and key role of physical belonging and has called it as rooted issue, according to which individuals stick the environment, along with its physical elements, in mind to form concept of belonging (Javan Foruzandeh and Motalebi, 2011: 32). Physical environment can affect personal attachment through meeting a part of material and spiritual needs of human. Belonging to the place would be continued and empowered, when there is a constructive interaction between needs of users and the environment. Meeting needs and providing functions are the main man-place interactions. Spatial dependence or functional belonging refer to ability of a place to empower people to achieve desirable goals and activities (Livingston \& Baileyand Kearns 2008: 1). Physical and functional qualities of place can affect a degree of belonging to place as a position for social activities and dealings $\mathrm{n}$ (Ujang, 2009: 158).

In addition to meet a level of human needs in process of activities (the factor can itself affect creation of attachment to place), Physical elements of the environment can play key role in determining individual, social and cultural identity of people. In this regard, Rappaport has emphasized role of social-cultural components in formation of physical environment or has presented theory of nonverbal communication to divide the environment to a series of fixed, semi-fixed and moving physical elements. From this perspective, people derive their desired concept and meaning based on their own cultural codes and symbols. In his opinion, place in this approach is changed into a symbolic place, in which each element indicates a part of social culture of the environment in symbolic form (Javan Foruzande and Motalebi, 2011:31). In this regard, in studies of Kevin Lynch (Lynch, 1997: 170-178), 
role and importance of physical factors in formation of significant relationship between person and place is emphasized. He has emphasized concepts such as structure or orientation, adaptability, transparency and legibility to consider role of physical factors. Another element is meaning of official structure, which refers to how to combine components in small scale and refers to concept of sense of navigation in large scale. Adaptability means that can single form of a place be adjusted with single form of its activities and features of a society? Transparency refers to direct perception of the environment by senses and legibility also refers to this issue that to what extent residents of a habitat can make proper relationships with each other through symbolic physical elements.

\section{DIFFERENT LEVELS OF SENSE OF PLACE}

$\begin{array}{ll}- & \text { Belief rootedness } \\ - & \text { Unconscious rootedness } \\ \text { - } & \text { Relative location } \\ \text { - } & \text { Alienation with place } \\ & \text { No place }\end{array}$

Steps of sense of place

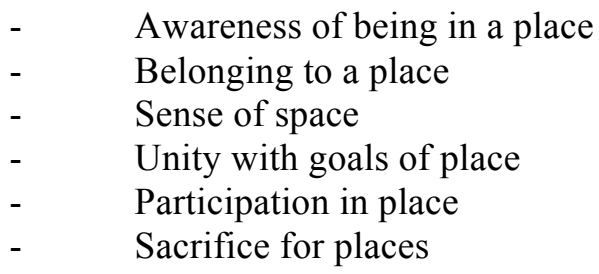

\section{HILD}

Child is a sense with age below 18 years old; unless lower legal age is determined based on national codes (Convention on the Rights of the Child, 1998, paragraph 1).

\section{ORPHAN CHILD}

It refers to a child who has no real supervisor and parent for some reasons permanently or temporarily (Instructions of Welfare Organization of Iran, 2000, p.5).

\section{FAMILY}

Family refers to members in home and relatives, spouse and children and parents. The desired concept by this study is parents and children as the smallest social unit.

Family: family refers to members separated from each other including father, mother and children and the element for unity of the family is divine gift called emotion. Family is the basic unit of the society and the main center for growth and transcendence of human.

Constitution of Islamic Republic of Iran has defined family as follows: family is the basic unit of the society and the main center for growth and transcendence of human and belief agreement for formation of family that can pave the way for interactional and growing movement of human. Providing facilities to achieve this goal is among responsibilities of Islamic Government.

\section{ORPHAN}

Orphan refers to a person who has lost father; an animal without mother and among birds, it refers to a chick without parents. In jewelry, the term can be applied for unique and precious object like Orphan Diamond, which refers to unique and precious diamond. The word "orphans" is applied for a plural form of orphan. When a boy grows up or a girl marries, they won't be called as orphan anymore.

\section{BOARDING CHILD}


It refers to Children who are far from their family for any reason and live in boarding centers (Babaei, 1990, p.9).

\section{CARE AND EDUCATION}

It refers to all professional activities in field of protecting rights and dignity of orphan children and adolescents and providing their physical and mental health and providing conditions for their spiritual, social and academic growth and their autonomy (Instructions of Welfare Organization of Iran, 2000, p.5).

Mentor or assistant refers to person who is responsible for caregiving to several children and in other words, mentor is Plenipotentiary Representative of boarding management.

\section{NURSERY}

It refers to a place to maintain children received from early ages to the end of age 5 and educate them.

\section{BOARDING}

It refers to a closed place, at which children live with each other far from their families. Nursery, orphanage, quasi-family and Center for Children are also synonyms for boarding. In other words, boarding is a place that encompasses some people who are deprived from their parents that are their divine emotion.

\section{CHILDHOOD}

Childhood refers properly to needs, mental points and special world of childhood. Childhood is considered as the first step of growth and in addition to be related to growth steps, it is independent stage of human life with specific encouragements and problems. Children are growing people, but related to their specific age group. They are people similar to others who attend activities of their world. Hence, after biologic aspect, it seems that childhood refers to a stage of organism growth that has been always existed; although it has been explored over the decades. In fact, the stage is the foundation for all periods of life (adolescence, youth and adulthood). The first stage of growth of children is to create absolute trust and to destroy distrust capacity in them.

According to emphasis on creating sense of belonging to the environment, when child enters to a properly designed internal space, sense of belonging would be created in him/her after seeing a space in accordance with his/her age and spirits. This is because; child feels satisfaction and tendency to trust in the environment introduced.

Through considering the concept of childhood and world of childhood, literature of children has been also created. Child literature refers to works created through recognizing needs of child to entertainment and considering qualities of mind and perception and emotions of children to fill their free times (Tabrizian, 2007: p.2).

\section{REASONS OF EMERGENCE OF CHILDHOOD}

Three factors are important in field of creation of concept of childhood. Two factors out of them are objective and the other one is subjective factor. Two objective factors are as follows:

1- $\quad$ Emergence and expansion of printing industry

2- $\quad$ prosperity of school and public education

Although both of these factors return to long past in historical terms, expansion of their achievement and effect is related to later times. Third factor is associated with the evolution created by opinions of two philosophers of $18^{\text {th }}$ century, John Luck and John Juke. They believed that education should be based on nature of child and John Luck has also referred for the first time to relationship of time process and human perception and has called child as a whole and has mentioned that growth of personality and body are as important as growth of rational abilities. When children used to be usually maintained at home, he claimed that children should be allowed to play in open space as much as possible. He believed that education for children should be through playing and entertainment and simple and understandable works, along with enjoy, should be provided for them (ibid, p.2-3). 


\section{HISTORY OF SUPPORTING ORPHANS}

Historical literature of supporting orphans across the world:

Social problems like poverty and needs, illness and disability and orphanage have been existed always over the history at human societies and different weaknesses have been also existed. Orphanage is one of the social natural phenomena existed in human societies since long ago. Protecting orphans has long history, so that Hamoorabi, king of Babel, has been responsible for caring widow women and orphans by 2000 years B.C. After the said history, no evidence is existed in this field to the early $16^{\text {th }}$ century. However, according to historical evidences of social life of human, supporting orphans and parentless children has been existed in majority of societies in a non-organized and non-professional manner under impact of charitable, humanitarian and religious incentives by people and social and religious institutes based on culture and beliefs of the societies.

Since early $16^{\text {th }}$ century, in some western countries, the issue of protecting and supporting the poor and orphans was considered in codified manner and through efforts of people affected by academic and thinking movements. The Act of ((Henry VIII)) was the first act in England to handle situation of the poor and by 1563, the government of the U.K enforced some regulations in field of the said act. By 1597, in order to care after disabled people, the old and blind people, special centers were established and there, special care used to be given to such people.

With the beginning of $17^{\text {th }}$ century, Poor Law ((Elizabeth I)) was enforced at the U.K. At the U.S.A, the first orphanage was established by 1740 and it was an institute to care after children who had lost their parents as a result of death of parents, divorce and poverty. The centers were historically among the first supporting centers in industrial countries of the West. Until before 1800 , there were only 7 institutes in U.S to give care to poor, homeless and left and criminal children. Each center used to be managed by private sector. By 1930, number of these centers in different regions of America reached 26 units to care after 2816 children (San'atinia, 1991, p.4, 5).

\section{HISTORICAL LITERATURE OF PROTECTION OF ORPHANS IN IRAN}

Historical evidences indicate that in Iran before Islam, in presence of all differentiations of poor and disable orphans; the society has had many centers to keep orphans and families used to care after such children based on their old religious traditions.

There is no codified evidence about formation and establishment of orphanages in Iran. According to available historical evidence till 1901, these centers have not been established in Iran till that time. In the first secret meeting to prepare constitutionalism by Feb $23^{\text {rd }} 1905$ at the house of Nazem U1Asalem Kermani, a part of the book "Ibrahim Beig" referring to interior minister can indicate lack of such center named orphanage to maintain and educate orphans.

Since about 100 years ago, with the entrance of some issues from West to Iran, the phenomenon of orphanage was also entered to Iran, so that evidences indicate that in more than 100 years ago, no orphanage has been existed in Iran and there has been only one place that has been established by Germany Government in Khui City for this purpose. As it is mentioned in Logbook of Ibrahim Beig, the thought of establishment of orphanage in Iran was for the first time for Naseredin Shah as a result of his travel to abroad and some signs of it are clear in Logbook of Ibrahim Beig (San'atinia, 1991).

\section{ORPHANAGE PHENOMENON AND FACTORS AFFECTING IT}

The motivations and reasons for sending children to boarding centers:

Factors that can make children to be sent to boarding centers by family or other authorities can be divided to 2 general groups as follows:

\section{NATURAL FACTORS:}

Human societies have faced always natural disasters and events like flood, earthquake, Drought, hunger and other problems, as a result of which some children used to lose their parents and relatives and become orphan and as a result, the society and government were responsible for protecting them in a specific manner. Although the disasters have abundant bitterness and challenges, the happiness 
remains in terms of acceptance of the children and caring after them by relatives and humanitarian and kind people (e.g. earthquake of June of 1991 in Gilan and Zanjan).

Unnatural factors:

These factors are various and are mostly in form of individual, family and social factors and as a result of lack of proper performance and behavior of family and society against them and each other. Most cases of reception of orphans in Welfare Organization are for these unnatural factors:

1- $\quad$ Unknown place of parents

2- $\quad$ Divorce and separation of parents

3- $\quad$ The death of parents or one of them

4- $\quad$ Leaving family by father

5- $\quad$ Addiction of the parents or one of them

6- Moral-social incompetence of parents

7- $\quad$ Incurable disease of Parents

8- $\quad$ The economic poverty of parents

9- Missing parents

10- Disorientation, confusion and incompatibility

11- Betrayal of both parents

12- Religious and class differences between parents

13- The large number of children in the family

14- Stepfather in the family

15- $\quad$ Stepmother in the family

16- Remarried parents

17- The imprisonment of parents or one of them

18- inadequate housing and Location

19- escape of Children from families because of having a violent, tyrannical and unstable family

20- Ostracized and abandoned children in the community and public places (San'atinia, 1991).

The mentioned factors are the factors for reception of orphans in welfare organization centers and clearly, all of them are resulted from unorganized family in comprehensive aspects that can pave the way for many Prosperity and adversity of family.

\section{PROBLEMS OF ORPHANS}

Identity-personality problems:

Being separated from family, lack of experiencing dominant relationship among family members, lack of sense of belonging to special society, special place and special identity make the children confused in childhood and create main personality and behaviors problem for them in future. Closeness of maintenance system of these children to family system plays key role in meeting the main problem.

\section{SOCIAL PROBLEMS}

Separation of these children from society and people, maintenance of them in places that are managed in public manner and in form of institute can prevent them to have social relations and even being in contact with daily challenges in the society that have become common for ordinary people.

Therefore, it seems that systems and processes of designing these places should be in such a manner that they can reconstruct fluidity and current of life out of these places in smaller scale on one hand. On the other hand, they should enable children in these places to be in contact with the outside environment, so that the complex can be something more than a place with Impenetrable fences.

\section{COMPARING FUNCTION OF HOME AND ORPHANAGE}

- Function of home and orphanage: 
In family institute, children are under fixed education and protection. In this process, family can be considered as the focus of love and kindness and training emotions and transferring civilization and culture to child and can result in evolution and mental and social balance of child. However, no fixed and specific pattern in orphanage is existed to train children during living in orphanage with different people and different characters and beliefs.

In orphanage system, children can attach to no one and can feel no one of her/him. Employees come on certain time and go on certain time. Nothing is fixed for children. In short, personality of children in orphanage is considered as a game and sense of belonging is not remained for them through such dual personality.

Social relationship of family and lack of it in orphanage:

Children grown up in family and experienced social events and have had relationship with other relatives and friends and individuals are normal and active people, who are able to manage their life with their self-confidence.

However, for children of boarding centers, there is no possibility to communicate family members and social institutes. Therefore, they grow up in a closed environment and can't gain social and normal personality. Hence, the individuals are mostly weak and dependent on others with specific behavior and unable to solve their own problems.

Psychologists and sociologists believe that the best environment for growth of spirits of children and stylizing their emotions is family. In addition to food and clothes, children need kindness of their parents and children who are deprived from such kindness and live in boarding environments like nurseries and orphanages and other centers suffer mostly from mental disabilities and nervous disorders.

Love of a woman or a man can satisfy soul of only one or two children; although it can't be useful for 50 children in an orphanage. Love and kindness of a caregiver by itself can't stylize and grow emotions and feelings of the children. Hence, many old and new thinkers and psychologists consider family as the best environment for physical and mental growth of children and consider orphanage as a prison for body and soul of child. This has been also emphasized by Islam and it believes that maintaining children in public places and providing food and clothes for them is not enough, so that they can be grown up in family and be behaved with kindness and love.

In this filed, Prophet Mohammad has mentioned that "the best home is that home, at which an orphan is behaved with kindness and love and the worse home is that home, at which an orphan is behaved with violence".

\section{WHAT SPACE CHILDREN LIKE?}

Children are mostly interested in places where they can play during the day. Children implement what is in their imagination during playing games. They need an adequate space to implement the imaginations. Spaces should be designed in such manner that the imaginations are not limited to children and they can change them constantly. Training spaces of children should create a part of sense of peace and attraction of House for Children. in such place, children feel as they are in their own home and they like to enter such places and are interested in it (Dehghani, 1997; p.29).

Division of the space to some sections with different degrees of utilization and variety of using it is interested by children. Children need open space, so that the spaces can provide conditions for their mobility and activities, noisy games, child activities, jumping and running for them. One of the certain useful indices of educational and training buildings is to have enough space for mobility of children.

Finally, the more the authorities are able to make relationship between children and sky, green space and nature and open land, the more the desired space is created for them and this is same environment that can empower creativity and innovation of children (ibid, p.30). 
Through considering designation and materials, a space should be created with following features:

- $\quad$ Children can feel safe there

- $\quad$ Be adjusted with the natural environment

- Rooms, classrooms and other spaces should be categorized. The categorization can enhance ability of recognition of children and at the same time, children can feel themselves as members of a large society.

- Internal spaces should be designed in such manner that they can motivate sense of curiosity of children. Structural elements like columns, beams, main beams and walls should demonstrate their duty and children should feel energy and power of the elements and perceive skeleton of the loading structure through their sense of curiosity.

- $\quad$ Creating a happy and hopeful space.

Through designation and materials, happy and hopeful space should be created. Sloped colorful roofs maintained by columns and beams, transparency and natural lighting in spaces, using colorful elements are good instruments to create a happy and hopeful space. Colors remind different concepts for children.

\section{CONCLUSION}

Children are able to recognize a building among other building while evaluation of a situation and can distinguish buildings; although differentiation of people and their activities is difficult. In this regard, people and their activities are more important than architecture for children. Moreover, this issue is originated in a reality that claims that human and his activities refer to functional features and characteristics more than quality of constructed environment around them. Because of same condition and same preference, children are prepared to accept a good and beautiful form to cover their shortcomings. Beauty of objects emphasizes a function not only in view of children, but also in view of adults. Hence, one architect has mentioned that clearly, legibility degree can't be determined by architecture, but also it can be determined through transfer of contractual concepts to use constructional materials and functional facilities.

Contractual concepts, along with variety of motivations and stimuli of life and their functions, can be considered as a primary challenge and especially a competitor for architecture, which can invite young architects to use output of this work. As a result, these issues would be realized by children. Hence, nature is a complementary member for the manmade environment. Combination with environmental texture is an irrevocable issue; although in texture that the building is related to children.

Children are accustomed to things in their life automatically and actively. Hence, it is not surprising if they want participate in forming their daily life and changing it and don't want to cope with predetermined conditions. Confirmation and acceptance of change in home for children can clearly reflect identity motivations, which are introduced by children and are resulted from their perceptions.

Moreover, children should be able to be developed independently regardless of many limitations on behalf of teachers and authorities. The mentioned issues can create tendency to enhance selfconfidence and learning, along with innovation and reaction to challenges, sense of responsibility, learning new skills and sense of being systematic and valuable.

\section{DESIGNING STRATEGIES}

Today, it has been proved that children by themselves need no physical protection, but also all of their existential dimensions (mental, emotional, personality, intellectual, cognitive and moral dimensions) should be considered.

1- $\quad$ Eliminating and changing dormitory and public salons to suites

2- $\quad$ Dividing and sectioning residential units to private and public sections

3- $\quad$ Designing personal facilities like cage, bed and other personal facilities 
4- $\quad$ Creating a space between complex and district that can lead to make communication between children of the complex and other children.

5- $\quad$ In order to avoid distract others; a sitting room should be designed for residents of every several rooms.

6- $\quad$ Creating intangible border between the complex and surrounding area (eliminating fens and impermeable walls)

7- $\quad$ Presence of children in context of common and routine activities of people

8- $\quad$ Designing residential units beside each other as intimate neighbor units

9- $\quad$ Designing residential units responsible for certain number of individuals

10- $\quad$ Creating features and spaces of a house in units

11- Psychology study of children and recognition of spaces, colors and textures interested by children

12- Considering principles and standards of designing spaces based on physical dimensions of children

13- $\quad$ Paying attention to principles of safety and firefighting

14- $\quad$ Creating suitable landscapes between closed and natural space

15- Creating physical relationship between internal and external space

16- $\quad$ Using flowers and plants in space

17- Creating spaces with suitable colors and contrast

18- $\quad$ Creating green balance in floors

\section{REFERENCES}

Barahani, MT, Hilgard Psychology Field

Bran Erick, (1994), trans. I Mofazah, Tehran, games (psychology of human relations)

Partovi, P, (2003), place and no place, psychological approach, Magazine of Fine Arts, No.145, p.4247

Piaget, J, Handy Simon, P, (1987), child psychology and educational principles of youth, trans. E Shakibapoor, Nima Bookshop

Daneshvar, MA, Child Psychology, Publications of Tabriz University

Rankle, H Edward, "Education without screaming"

Riahi, Gh, (1996), secrect of world of childhood, Eshraqieh Press

Safarinia M, Saberi M, (1999), basis of psychology of child growth, Agah Sazan Press

Falahat M.S, (2005), role of physical design in sense of place, Magazine of Fine Arts, Tehran, No.22, p.35-42

Cloud $\mathrm{H}$, children and their boundaries

Study of papers and information of Welfare Organization of Tehran and Shemiranat City

Using information of officials of Amaneh Nursery and Shahid Ghodusi Complex

Altman,1\& sethalow(ed) (1992),"place attachment", plenum press, New York.

Canter,D.(1971),"the psychology of place", The Architectal press,London.

Relph,E.(1976),"place and placelessness", pion,London.

shamai, shmuel(1991),"sense of place :An empricial measurement “ „Isreael , Geoforum volume 22,pp.347-358.

steele ,Fritz (1981)," The sense of place”, CB Ipublishing company, Boston.

Eckenrode, J., Rowe, E., Laird, M., \& Brathwaite, J., (1994). Mobility as a mediator of the effects of child maltreatment on academic performance. Child development, 66(4), 1130-1142.

Fox, A., Berrick, J. D., \& Frasch, K. (2008). Safety, family, permanency, and child well-being: wath we can learn from children. Child Welfare League of America.

Gerhart, R.,\& Gerhart M. (2011). Christian orphanages: A directory. Retrieved from http://www.missionfinder.org/orphanages.htm

Ghera, M.M., Marshall, P. J., Fox, N. A., Zeanch, C. H., Nelson, C. A., Smyke, A. T., \&Guthrie, D. (2009). The effects of foster care intervention on socially deprived institutionalized children's attention and positive affect: results from the BEIP study.

McKenzie, R. (2010, January 14) The best thing about orphanages. The Wall Street Journal. Retrieved from http://online.wsj.com/article/SB10001424052748703510304574626080835477074.html 
McKenzie, R. B. (1999a). Orphanage Alumni: How they have done and how the evaluate their experience. In R. B. McKenzie (Ed.), Rethinking orphanages in the $21^{\text {st }}$ century (1-20). Thousands Oaks, CA: Sage Publications, Inc.

McKenzie, R. B. (1999b). Rethinking orphanages, In R. B. McKenzie (Ed.), Rethinking orphanages in the $21^{\text {st }}$ century (1-20), Thousand Oaks, CA: Sage Publications, Inc.

McKenzie, R. (1999c). Rethinking orphanages for the $21^{\text {st }}$ century: A search for reform of the nation's child welfare system, In R. B. McKenzie (Ed.), Rethinking orphanages in the $21^{\text {st }}$ century (289-301), Thousand Oaks, CA: Sage Publications, Inc. 